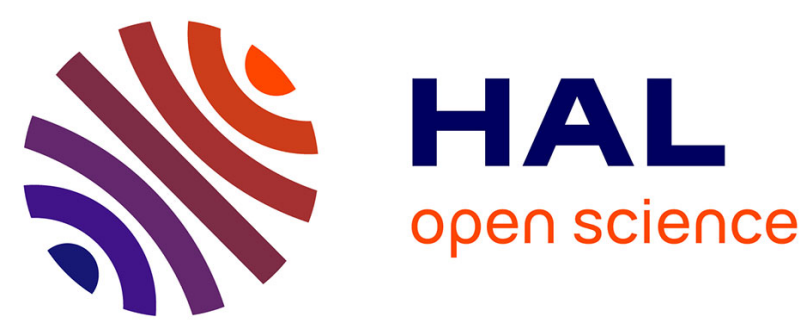

\title{
The 2006 slow slip event and nonvolcanic tremor in the Mexican subduction zone
}

\author{
Vladimir Kostoglodov, Allen Husker, Nikolai M. Shapiro, Juan S. Payero, \\ Michel Campillo, Nathalie Cotte, Robert Clayton
}

\section{To cite this version:}

Vladimir Kostoglodov, Allen Husker, Nikolai M. Shapiro, Juan S. Payero, Michel Campillo, et al.. The 2006 slow slip event and nonvolcanic tremor in the Mexican subduction zone. Geophysical Research Letters, 2010, 37 (24), pp.24301. 10.1029/2010GL045424 . insu-00565049

\section{HAL Id: insu-00565049 \\ https://hal-insu.archives-ouvertes.fr/insu-00565049}

Submitted on 27 May 2020

HAL is a multi-disciplinary open access archive for the deposit and dissemination of scientific research documents, whether they are published or not. The documents may come from teaching and research institutions in France or abroad, or from public or private research centers.
L'archive ouverte pluridisciplinaire HAL, est destinée au dépôt et à la diffusion de documents scientifiques de niveau recherche, publiés ou non, émanant des établissements d'enseignement et de recherche français ou étrangers, des laboratoires publics ou privés. 


\title{
The 2006 slow slip event and nonvolcanic tremor in the Mexican subduction zone
}

\author{
Vladimir Kostoglodov, ${ }^{1}$ Allen Husker, ${ }^{1}$ Nikolai M. Shapiro, ${ }^{2}$ Juan S. Payero, ${ }^{1}$ \\ Michel Campillo, ${ }^{3}$ Nathalie Cotte, ${ }^{3}$ and Robert Clayton ${ }^{4}$ \\ Received 8 September 2010; revised 13 October 2010; accepted 18 October 2010; published 16 December 2010.
}

[1] The last decade featured an explosive sequence of discoveries of slow slip events (SSE) and nonvolcanic tremor (NVT) in different subduction zones and continental faults. Many observations show that SSE is usually associated with an increased NVT activity but it is not clear yet if those events are the result of the same process or are independent expressions of a common underlying seismotectonic source. A large SSE in Central Mexico occurred in 2006 during the Meso-American Subduction Experiment (MASE) which provided continuous observations of the NVT for the years 2005-2007. GPS and abundant seismic data show that although the NVT energy increased notably during the 2006 SSE, the two phenomena were separated spatially and not completely synchronized in time. Significant NVT episodes occur during the period between SSEs, suggesting again that large slow slip events and NVT observed in the Mexican subduction zone are of different origins. The results presented here contribute to uncovering the nature of these two separate phenomena that have been indistinguishable in some other regions. Citation: Kostoglodov, V., A. Husker, N. M. Shapiro, J. S. Payero, M. Campillo, N. Cotte, and R. Clayton (2010), The 2006 slow slip event and nonvolcanic tremor in the Mexican subduction zone, Geophys. Res. Lett., 37, L24301, doi:10.1029/2010GL045424.

\section{Introduction}

[2] There is a growing scientific challenge to understand the origin of the slow slip events (SSE) [Schwartz and Rokosky, 2007] and nonvolcanic tremor (NVT) [Obara, 2002; Rubinstein et al., 2010]. SSE and NVT observed now in different subduction zones may be a very important constituent in the cycle of large subduction thrust earthquakes. Many studies show that SSE is often associated temporally and spatially with increased NVT activity. Comprehensive investigations of NVT and short-term SSE in the subduction zones of Japan and Cascadia supported mainly the hypothesis that these events occur simultaneously, and most likely on the same plate interface [ $\mathrm{La}$ Rocca et al., 2010; Obara and Hirose, 2006; Obara et al.,

\footnotetext{
${ }^{1}$ Instituto de Geofísica, Universidad Nacional Autónoma de México, Mexico City, Mexico.

${ }^{2}$ Laboratoire de Sismologie, Institut de Physique du Globe de Paris, Paris, France.

${ }^{3}$ Laboratoire de Géophysique Interne et Tectonophysique, Université Joseph Fourier, Grenoble, France.

${ }^{4}$ Seismological Laboratory, California Institute of Technology, Pasadena, California, USA.

Copyright 2010 by the American Geophysical Union. 0094-8276/10/2010GL045424
}

2004; Peterson and Christensen, 2009; Rogers and Dragert, 2003]. This results in a view that the so called episodic tremor and slip (ETS) events [Rogers and Dragert, 2003] are just short-duration SSE and NVT, and are closely associated both in time and space [Shelly et al., 2007; Wech et al., 2009]. The NVT bursts detected by seismometers in Japan probably consist of a large number of small magnitude low frequency earthquakes [Shelly et al., 2006], whose combined slip on the fault may contribute additionally to the crustal deformations produced by concurrent slow slip events.

[3] Some observations nevertheless show that SSE and NVT are not systematically associated in the form of ETS. There are examples of NVT episodes happening without any geodetically (GPS) detectable SSE, (southwest Japan [Obara et al., 2010], Cascadia [Wech et al., 2009], Mexico [Vergnolle et al., 2010]), and also the opposite situation when large, long-term SSEs occur without any detectable NVT [Delahaye et al., 2009; McCaffrey et al., 2008]. Unfortunately, the small magnitude tremor and slow slip events cannot be analyzed in detail, particularly in the regions of steeply dipping subducted slabs. The subduction zone in Central Mexico provides a favorable opportunity for the study of NVT and SSE because of its unusual subhorizontal plate interface and its large periodic slow slip events of $M_{\mathrm{w}} \sim 7.5$ [Cotte et al., 2009; Kostoglodov et al., 2003].

\section{Seismic Data and Analysis}

[4] A large SSE in Central Mexico occurred in 2006 during the Mezo-American Subduction Experiment (MASE) which provided an important set of seismological data making it possible to assess the properties of NVT in the region (Figure 1). There were 100 broad-band seismic stations installed approximately every $\sim 6 \mathrm{~km}$ along the profile running almost perpendicular to the Pacific coast of Mexico, from Acapulco to over $550 \mathrm{~km}$ inland [Pérez-Campos et al., 2008]. Unfortunately, in spite of excellent along profile space resolution of the MASE data those do not provide an adequate $2 \mathrm{D}$ coverage for accurate hypocentral estimates [Payero et al., 2008].

[5] The common approach in the NVT research consists in applying different methods of tremor detection with the records of different stations, then merging them for source location [Kao and Shan, 2004; La Rocca et al., 2009; Obara, 2002; Shelly et al., 2007]. In general, the precise hypocenter estimation of the NVT is still problematic due to the low signal to noise ratio and the lack of identification of coherent seismic phases. In the absence of a complete set of precise NVT locations a simple way to describe the tremor 


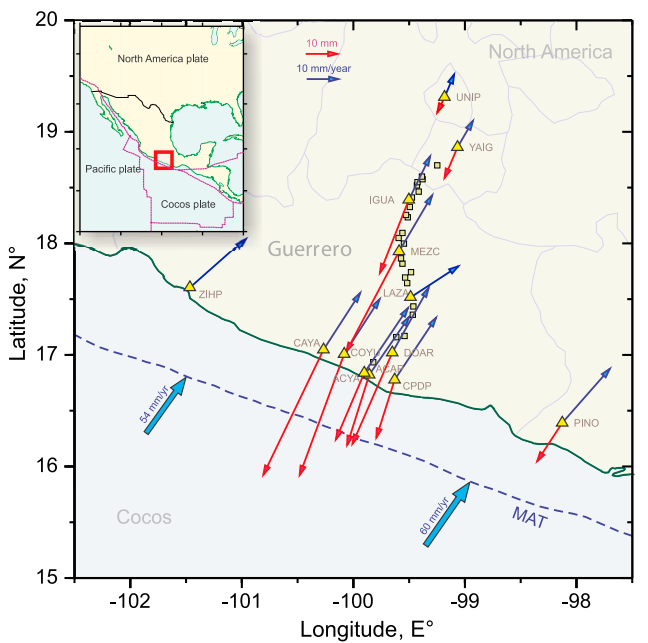

Figure 1. Central Mexico study area (red square, inset). Triangles show positions of permanent GPS stations. Blue vectors are velocities (mm/year) of secular motion of the GPS stations and red vectors are total displacements $(\mathrm{mm})$ produced by $2006 \mathrm{SSE}$. Scale vectors of $10 \mathrm{~mm}$ and $10 \mathrm{~mm} /$ year are in the upper part of the Figure. Small green squares show locations of the MASE broad band seismic stations used for this study. MAT - Middle America Trench shown by dashed line. Thick annotated arrows represent the convergence rate between the Cocos and North America plates [DeMets et al., 1994]. All displacements and velocities are shown with respect to the fixed North America plate. The 2006 SSE displacement at ZIHP is almost zero. LAZA station was installed during the SSE and did not record the complete slow slip displacement.

activity in time is the differential duration of tremor (DDT) episodes [e.g., Payero et al., 2008; Shelly et al., 2007], which disregards their magnitudes. The DDT is tied to the NVT intensity with time since the average tremor amplitudes seem to be invariant to the NVT bursts duration [Aguiar et al., 2009].

[6] To avoid the difficulties related to tremor source location from the MASE data and at the same time to characterize their duration and intensity, we apply an "energy" inference [Kostoglodov et al., 2008]. The tremor wave-train develops mainly between $0.5-15 \mathrm{~Hz}$ but at most of the MASE stations (Figure S1 of the auxiliary material) the best signal to noise ratio is in the $1-2 \mathrm{~Hz}$ frequency range. ${ }^{1}$ Therefore, the first step in our energy approach is to filter signals between 1 and $2 \mathrm{~Hz}$ and to compute their energy (squared velocity). To obtain comparable NVT energy assessments at every seismic station, it is necessary to correct the records for the site effects after individual background noise reduction. The site effects are estimated using the coda calibration method [Husker et al., 2010]. We then apply a median filter to smooth the entire waveforms and a threshold cutoff procedure to compile a complete register (a list of initial time and duration) of NVT recorded with the MASE seismic stations for 2005-2007. The NVT register was compiled using data from 24 MASE stations, which had acceptable signal-to-noise ratio. A space-time

\footnotetext{
${ }^{1}$ Auxiliary materials are available in the HTML. doi:10.1029/ 2010GL045424.
}

distribution of the total NVT radiated energy in $1-2 \mathrm{~Hz}$ bandwidth was obtained via integration in time and interpolation in space (Figure 2). It is clearly seen that the NVT seismic energy was radiated to the seismic stations located predominantly above the subhorizontal interplate contact segment, which is at approximately $40 \mathrm{~km}$ depth, between 170 and $260 \mathrm{~km}$ from the trench. A maximum of the NVT energy attenuation curve (Figure S2) constrains the location of tremor bursts located along the MASE profile. Thus, the space distribution of the maximum energy release (Figure 2) corresponds to the locations of the NVT sources.

\section{GPS Data Modeling}

[7] Surface displacements produced by the 2006 slow slip event were measured by permanent GPS stations, most of them located in Guerrero, Central Mexico [Larson et al., 2007] along the MASE seismic profile (Figure 1). The largest displacements, up to $4.4 \mathrm{~cm}$, are observed at the coastal area. The onset and duration of the 2006 SSE were estimated by fitting a sigmoid function to the GPS horizontal components records reduced for the inter-SSE trend at each GPS station (Figure 2). The total final displacements during the SSE with respect to the North America plate were determined (after adding the trends back in) as a difference between maximum and minimum of the fitting function. Dislocation models [Savage, 1983] that best fit the total final displacements during the 2006 SSE (Figure S3) require that most of the slow slip (with a maximum of about $19 \mathrm{~cm}$ ) occurred on the transition zone of the plate interface, a segment about $80-90 \mathrm{~km}$ long located between the seismogenic coupled zone (45-75 km from the trench), and a presumably freely slipping zone (Figure 2). The model provides an acceptable fit to the data when the inland tip of the SSE zone expands some 10-15 km more into the NVT source area, but the slip on the downdip dislocation patch in this case needs to be notably reduced.

[8] It should be noted that the forward static modeling of the final GPS displacements along the 1D transect provides better constraints on the location of transient segments and the amount of fault slip. An attempt to invert the GPS time series of the 2006 SSE [Larson et al., 2007] using the Network Inversion Filter (NIF) [Segall and Matthews, 1997] generates excessive inland extension of the slow slip on the plate interface due to very poor approximation of the vertical component time series. Modeling the previous 2002 Guerrero SSE [Iglesias et al., 2004; Kostoglodov et al., 2003; Yoshioka et al., 2004] determined that almost all the slip was released on the transient segment of subduction interface limited to $\sim 170 \mathrm{~km}$ inland from the trench.

\section{Results}

[9] Figure 2 summarizes the main results of this study. The energy distribution suggests that the NVT is mainly located within or above the deep free slipping patch of the plate interface (at 170-250 km from the trench). Indeed, a previous study [Payero et al., 2008] which analyzed more than one hundred strong individual NVT episodes in Guerrero reported locations of those tremors which coincide with the NVT energy release area and reported location depths mostly distributed over the lower continental crust and plate contact zone. The 2006 SSE transient dislocation 


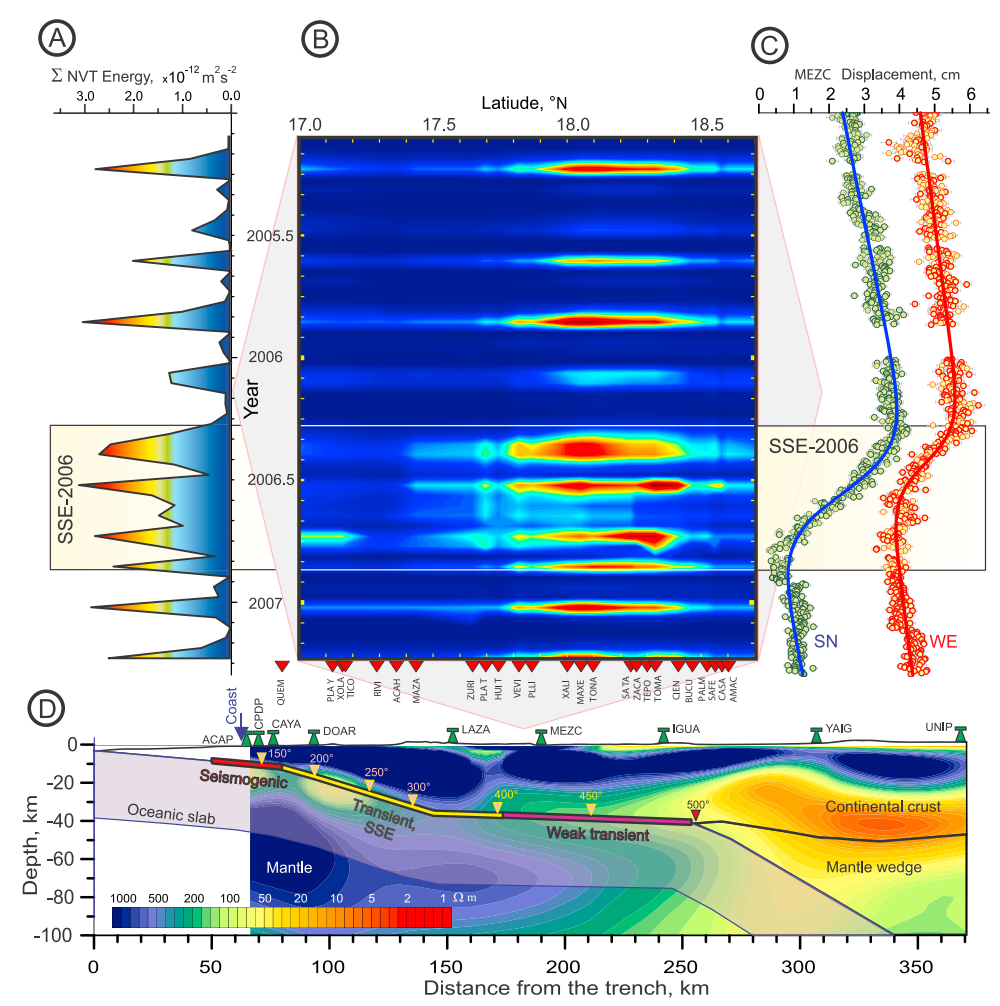

Figure 2. (a) Time distribution of all the (1-2 Hz) NVT seismic energy recorded during the MASE experiment. Energy color scale is the same as in Figure 2b. (b) Time-Distance distribution of the NVT energy (average smoothing with the moving time window of 15 days) along the MASE profile. Red annotated triangles indicate locations of seismic stations. (c) Daily time series at MEZC GPS station located approximately in the middle of the MASE profile (see Figure 1). Time scale is the same as in A and B. SN, WE - South-North and West-East components, respectively. SSE-2006 annotated rectangle delimits the period of the 2006 slow slip event. (d) Subducting Cocos - North America plates interface in the study area according to [Kim et al., 2010]. The background image is a resistivity model [Jödicke et al., 2006]. Inverted pink triangles are annotated with the temperature ${ }^{\circ} \mathrm{C}$, which is modeled on the plate interface [Manea et al., 2004]. Green antenna-like symbols show projections of the GPS station locations on the MASE transect. Figures $2 \mathrm{a}-2 \mathrm{c}$ have the same time scale. Figures $2 \mathrm{~b}$ and $2 \mathrm{~d}$ are aligned so that the zone where tremor was detected can be compared to the plate configuration.

is determined immediately updip of this zone, which means that the SSE and NVT are spatially separated. This observation agrees with the SSE and NVT study in Oaxaca, Mexico subduction zone [Brudzinski et al., 2010]. Four large distinct NVT burst episodes occurred during the lone 2006 SSE. However, there were several comparably long lasting and intensive NVT episodes during the "quiet" epochs when no apparent SSE was detected by GPS (except perhaps a poorly resolved short-term SSE in March 2005 [Vergnolle et al., 2010]). The lack of simultaneity between NVT and long term SSE suggests that they are not an expression of the same underlying process.

[10] We applied a simple method to evaluate an upper limit of the total seismic energy radiated in all NVT episodes during the 2006 SSE from the estimated ratio of the energy power spectrum in 1-2 $\mathrm{Hz}$ band and the total energy of the NVT (see auxiliary material). If all NVT events were occurring on the same fault (plate interface) coherently with similar seismic slip rakes, then the total fault slip produced by all NVT events during the 2006 SSE would be of order $10^{-3}-10^{-4} \mathrm{~cm}$. This value is negligible compared to the average modeled dislocation $(\sim 10 \mathrm{~cm})$ of the SSE. The upper limit of the NVT slip is assessed applying a number of generous assumptions, and hence the real value can be even smaller. The surface expression of this NVT slip can not be measured by modern GPS techniques. This may explain why GPS data do not exhibit any notable surface displacements produced by large NVT episodes during the interSSE epochs. The slip detected during the NVT events in Japan [Obara et al., 2004] by the high sensitivity borehole tiltmeters was apparently produced by concurrent short-term SSE.

[11] Equivalent magnitude of the $2006 \operatorname{SSE}\left(M_{\mathrm{W}} \sim 7\right)$ is more than three orders larger than the magnitude of the combined NVT episodes $\left(M_{\mathrm{E}} 3.3\right)$ occurring during the period of slip. This discrepancy can be attributed to the space separation and different total duration of both phenomena. Surprisingly, a difference of the same order was reported for the SSE $\left(M_{\mathrm{w}} 6.7\right)$ and NVT $\left(M_{\mathrm{w}} 3.7\right)$ moment magnitudes estimates in the Cascadia subduction zone [Kao et al., 2009] where both type of events are very consistent in space and time.

[12] Two types of slow slip events reported in southwest Japan subduction zone [Hirose and Obara, 2005] are the long-term and short-term SSE, both accompanied by NVT, however, the accompanying NVT activity is different. During the long-term SSE, the NVT activity is only slightly intensified [Obara et al., 2010]. The source area of the short-term SSE is deeper than that of the long-term SSE [Hirose and Obara, 2005]. This observation would be in 
agreement with the results of this study if the short-term and small magnitude SSE recently detected in Guerrero [Vergnolle et al., 2010] were occurring in the NVT area of the subduction zone. Reliable modeling of the fault slip locations of these mini-SSE is still problematic because the corresponding displacements recorded by GPS are almost at the noise level of the position time series.

\section{Discussion}

[13] To date, there are several reliable observations in different subduction zones which suggest the existence of two distinct phenomena: large aseismic slow slip events (SSE) and the NVT episodes. Long term SSE and NVT recorded in the Mexican subduction zone are separated spatially and are not strictly correlated in time, although the NVT activity is strongly intensified by large SSE. Triggering of NVT by stress transients has been documented [Rubinstein et al., 2007] and the mechanism of this interaction, as well as the origin of SSE and NVT, is still in dispute.

[14] There is an obvious progression of seismotectonic segmentation of the subduction plate interface in Mexico (Figure 2d): the low-temperature, shallow weakly-coupled accretional segment; the seismogenic strongly-coupled section $\left(\mathrm{T} \sim 150 \mathrm{C}^{\circ}\right)$; then the zone where the transient SSE occur $\left(\mathrm{T} \approx 170-400 \mathrm{C}^{\circ}\right)$; and finally a supposedly "free slipping" zone above which the NVT occur $\left(\mathrm{T}=400-500 \mathrm{C}^{\circ}\right)$. Each section has its specific elastic strain accumulation and rebound regime with different recurrence times of the events (order of $10-10^{2}$ years for the subduction thrust earthquakes, $10^{-1}-10$ years for the SSE and days-months for the NVT).

[15] The modeling of the GPS data (Figures 2 and S3) locates the seismogenic coupled zone at shallow depth, with almost the same width and position as the source area of the $1962 M_{\mathrm{w}} \sim 7.0$ Acapulco earthquake doublet [Ortiz et al., 2000]. The transient SSE segment matches the ultra-slow velocity layer (USL) discovered in Guerrero on the top of the subducting plate [Kim et al., 2010; Song et al., 2009], and the tremor generating zone [Payero et al., 2008] corresponds to the higher conductivity area of the continental crust [Jödicke et al., 2006] over the "free-slipping" segment of the plate interface. The free slip condition is only an abstraction used for the SSE modeling. In reality the subducting oceanic plate should interact with the overriding continental plate on this weak interplate segment too, probably through a low viscosity layer [Hilairet et al., 2007; Kostoglodov, 1988] similar to the USL, and transmit some shear stress to the upper plate. The accumulated strain in the continental plate may be periodically released by the NVT and small magnitude SSE.

[16] Our observations and modeling results suggest the existence of two essentially different stages in the prograding process of the strain rebound on the downward portion of the subduction plate interface: the long-term SSE and NVT. The SSE doesn't produce seismic radiation (at least above the noise level at current instrumentation) and it is a creep-like slip episode. Slow slip modulates NVT activity by increasing the shear stress and dilatation over the downdip plate interface in the area where appropriate conditions exist for the NVT incidence. There is an observation of temporal coincidence of long-term SSE and neighboring NVT in the Bungo channel, SW Japan [Obara et al., 2010]. In the Mexican subduction zone these two phenomena are separated in space and are not necessarily synchronized in time.

[17] Now it is confirmed from a number of observations in different subduction zones including Mexico that some SSE (at least long term events) lack the concurrent detectable tremor in the same area. Nevertheless, based on our results it is not yet clear if the NVT may happen without short term SSEs which are still undetectable by the current GPS networks. Future studies in different subduction zones should verify this hypothesis which is important to understand the origin of the SSE and NVT.

[18] Acknowledgments. This study was supported by PAPIIT IN103808, CONACYT 84544, SEP-CONACYT-ANUIES-ECOS M06U02, I832 (G-GAP) ANR, ANR-06-CEXC-005 (COHERSIS), and ERC advanced 227507 "WHISPER" grants. The MASE experiment of the Caltech Tectonics Observatory was funded by the Gordon and Betty Moore Foundation. Contribution 82 from the Caltech Tectonics Observatory.

\section{References}

Aguiar, A. C., T. I. Melbourne, and C. W. Scrivner (2009), Moment release rate of Cascadia tremor constrained by GPS, J. Geophys. Res., 114 B00A05, doi:10.1029/2008JB005909.

Brudzinski, M. R., H. R. Hinojosa-Prieto, K. M. Schlanser, E. CabralCano, A. Arciniega-Ceballos, O. Diaz-Molina, and C. DeMets (2010), Nonvolcanic tremor along the Oaxaca segment of the Middle America subduction zone, J. Geophys. Res., 115, B00A23, doi:10.1029/ 2008JB006061.

Cotte, N., A. Walpersdorf, V. Kostoglodov, M. Vergnolle, J.-A. Santiago, I. Manighetti, and M. Campillo (2009), Anticipating the next large silent earthquake in Mexico, Eos Trans. $A G U$, 90(21), doi:10.1029 2009EO210002.

Delahaye, E. J., J. Townend, M. E. Reyners, and G. Rogers (2009), Microseismicity but no tremor accompanying slow slip in the Hikurangi subduction zone, New Zealand, Earth Planet. Sci. Lett., 277(1-2), 21-28, doi:10.1016/j.eps1.2008.09.038.

DeMets, C., R. G. Gordon, D. F. Argus, and S. Stein (1994), Effect of recent revisions to the geomagnetic reversal time scale on estimates of current plate motions, Geophys. Res. Lett., 21, 2191-2194, doi:10.1029/94GL02118.

Hilairet, N., B. Reynard, Y. Wang, I. Daniel, S. Merkel, N. Nishiyama, and S. Petitgirard (2007), High-pressure creep of serpentine, interseismic deformation, and initiation of subduction, Science, 318(5858), 1910-1913, doi:10.1126/science. 1148494

Hirose, H., and K. Obara (2005), Repeating short- and long-term slow slip events with deep tremor activity around the Bungo channel region, southwest Japan, Earth Planets Space, 57, 961-972.

Husker, A., S. Peyrat, N. Shapiro, and V. Kostoglodov (2010), Automatic non-volcanic tremor detection in the Mexican subduction zone, Geofis. Int., 49(1), 17-25.

Iglesias, A., S. K. Singh, A. R. Lowry, M. Santoyo, V. Kostoglodov, K. M. Larson, S. I. Franco-Sánchez, and T. Mikumo (2004), The silent earthquake of 2002 in the Guerrero seismic gap, Mexico $(\mathrm{Mw}=7.4)$ : Inversion of slip on the plate interface and some implications, Geofis. Int., 43(3), 309-317.

Jödicke, H., A. Jording, L. Ferrari, J. Arzate, K. Mezger, and L. Rüpke (2006), Fluid release from the subducted Cocos plate and partial melting of the crust deduced from magnetotelluric studies in southern Mexico: Implications for the generation of volcanism and subduction dynamics, J. Geophys. Res., 111, B08102, doi:10.1029/2005JB003739.

Kao, H., and S.-J. Shan (2004), The Source-Scanning Algorithm: Mapping the distribution of seismic sources in time and space, Geophys. J. Int., 157(2), 589-594, doi:10.1111/j.1365-246X.2004.02276.x.

Kao, H., S.-J. Shan, H. Dragert, and G. Rogers (2009), Northern Cascadia episodic tremor and slip: A decade of tremor observations from 1997 to 2007, J. Geophys. Res., 114, B00A12, doi:10.1029/2008JB006046.

Kim, Y., R. W. Clayton, and J. M. Jackson (2010), Geometry and seismic properties of the subducting Cocos plate in central Mexico, J. Geophys. Res., 115, B06310, doi:10.1029/2009JB006942.

Kostoglodov, V. (1988), Sediment subduction-A probable key for seismicity and tectonics at active plate boundaries, Geophys. J. Int., 94(1), $65-72$.

Kostoglodov, V., S. K. Singh, J. A. Santiago, S. I. Franco, K. M. Larson, A. R. Lowry, and R. Bilham (2003), A large silent earthquake in the 
Guerrero seismic gap, Mexico, Geophys. Res. Lett., 30(15), 1807, doi:10.1029/2003GL017219.

Kostoglodov, V., N. Shapiro, K. M. Larson, J. Payero, A. Husker, J. A. Santiago, and R. W. Clayton (2008), Nonvolcanic tremor activity is highly correlated with slow slip events, Eos Trans. $A G U, 89(53)$, Fall Meet. Suppl, Abstract U31B-05.

La Rocca, M., K. C. Creager, D. Galluzzo, S. Malone, J. E. Vidale, J. R. Sweet, and A. G. Wech (2009), Cascadia tremor located near plate interface constrained by S minus P wave times, Science, 323(5914), 620-623, doi:10.1126/science.1167112.

La Rocca, M., D. Galluzzo, S. Malone, W. McCausland, and E. Del Pezzo (2010), Array analysis and precise source location of deep tremor in Cascadia, J. Geophys. Res., 115, B00A20, doi:10.1029/2008JB006041.

Larson, K. M., V. Kostoglodov, S. Miyazaki, and J. A. S. Santiago (2007), The 2006 aseismic slow slip event in Guerrero, Mexico: New results from GPS, Geophys. Res. Lett., 34, L13309, doi:10.1029/2007GL029912.

Manea, V. C., M. Manea, V. Kostoglodov, C. A. Currie, and G. Sewell (2004), Thermal structure, coupling and metamorphism in the Mexican subduction zone beneath Guerrero, Geophys. J. Int., 158(2), 775-784, doi:10.1111/j.1365-246X.2004.02325.x.

McCaffrey, R., L. M. Wallace, and J. Beavan (2008), Slow slip and frictional transition at low temperature at the Hikurangi subduction zone, Nat. Geosci., 1(5), 316-320, doi:10.1038/ngeo178.

Obara, K. (2002), Nonvolcanic deep tremor associated with subduction in southwest Japan, Science, 296(5573), 1679-1681, doi:10.1126/science. 1070378 .

Obara, K., and H. Hirose (2006), Non-volcanic deep low-frequency tremors accompanying slow slips in the southwest Japan subduction zone, Tectonophysics, 417(1-2), 33-51, doi:10.1016/j.tecto.2005. 04.013 .

Obara, K., H. Hirose, F. Yamamizu, and K. Kasahara (2004), Episodic slow slip events accompanied by non-volcanic tremors in southwest Japan subduction zone, Geophys. Res. Lett., 31, L23602, doi:10.1029/ 2004GL020848.

Obara, K., S. Tanaka, T. Maeda, and T. Matsuzawa (2010), Depth-dependent activity of non-volcanic tremor in southwest Japan, Geophys. Res. Lett., 37, L13306, doi:10.1029/2010GL043679.

Ortiz, M., S. K. Singh, V. Kostoglodov, and J. Pacheco (2000), Source areas of the Acapulco-San Marcos, Mexico earthquakes of 1962 (M 7.1; 7.0) and 1957 (M 7.7), as constrained by tsunami and uplift records, Geofis. Int., 39(4), 337-348.

Payero, J. S., V. Kostoglodov, N. Shapiro, T. Mikumo, A. Iglesias, X. PérezCampos, and R. W. Clayton (2008), Nonvolcanic tremor observed in the Mexican subduction zone, Geophys. Res. Lett., 35, L07305, doi:10.1029/ 2007 GL032877.

Pérez-Campos, X., Y. Kim, A. Husker, P. M. Davis, R. W. Clayton, A. Iglesias, J. F. Pacheco, S. K. Singh, V. C. Manea, and M. Gurnis (2008), Horizontal subduction and truncation of the Cocos Plate beneath central Mexico, Geophys. Res. Lett., 35, L18303, doi:10.1029/ 2008 GL035127.

Peterson, C. L., and D. H. Christensen (2009), Possible relationship between nonvolcanic tremor and the 1998-2001 slow slip event, south central Alaska, J. Geophys. Res., 114, B06302, doi:10.1029/ 2008JB006096.
Rogers, G., and H. Dragert (2003), Episodic tremor and slip on the Cascadia subduction zone: The chatter of silent slip, Science, 300(5627), 1942-1943, doi:10.1126/science.1084783.

Rubinstein, J. L., J. E. Vidale, J. Gomberg, P. Bodin, K. C. Creager, and S. D. Malone (2007), Non-volcanic tremor driven by large transient shear stresses, Nature, 448(7153), 579-582, doi:10.1038/nature06017.

Rubinstein, J. L., D. R. Shelly, and W. L. Ellsworth (2010), Non-volcanic tremor: A window into the roots of fault zones, in New Frontiers in Integrated Solid Earth Sciences, edited by S. Cloetingh and J. Negendank, pp. 287-314, Springer, New York.

Savage, J. C. (1983), A dislocation model of strain accumulation and release at a subduction zone, J. Geophys. Res., 88(B6), 4984-4996, doi:10.1029/JB088iB06p04984.

Schwartz, S. Y., and J. M. Rokosky (2007), Slow slip events and seismic tremor at circum-Pacific subduction zones, Rev. Geophys., 45, RG3004, doi:10.1029/2006RG000208.

Segall, P., and M. Matthews (1997), Time dependent inversion of geodetic data, J. Geophys. Res., 102(B10), 22,391-22,409, doi:10.1029/ 97JB01795.

Shelly, D. R., G. C. Beroza, S. Ide, and S. Nakamula (2006), Lowfrequency earthquakes in Shikoku, Japan, and their relationship to episodic tremor and slip, Nature, 442(7099), 188-191, doi:10.1038/ nature04931.

Shelly, D. R., G. C. Beroza, and S. Ide (2007), Non-volcanic tremor and low-frequency earthquake swarms, Nature, 446(7133), 305-307, doi: 10.1038 /nature 05666 .

Song, T.-R. A., D. V. Helmberger, M. R. Brudzinski, R. W. Clayton, P. Davis, X. Perez-Campos, and S. K. Singh (2009), Subducting slab ultra-slow velocity layer coincident with silent earthquakes in southern Mexico, Science, 324(5926), 502-506.

Vergnolle, M., A. Walpersdorf, V. Kostoglodov, P. Tregoning, J. A. Santiago, N. Cotte, and S. I. Franco (2010), Slow slip events in Mexico revised from the processing of 11 year GPS observations, J. Geophys. Res., 115, B08403, doi:10.1029/2009JB006852.

Wech, A. G., K. C. Creager, and T. I. Melbourne (2009), Seismic and geodetic constraints on Cascadia slow slip, J. Geophys. Res., 114, B10316, doi:10.1029/2008JB006090.

Yoshioka, S., T. Mikumo, V. Kostoglodov, K. M. Larson, A. R. Lowry, and S. K. Singh (2004), Interplate coupling and a recent aseismic slow slip event in the Guerrero seismic gap of the Mexican subduction zone, as deduced from GPS data inversion using a Bayesian information criterion, Phys. Earth Planet. Inter., 146(3-4), 513-530, doi:10.1016/j.pepi. 2004.05.006

M. Campillo and N. Cotte, Laboratoire de Géophysique Interne et Tectonophysique, Université Joseph Fourier, BP 53, F-38041 Grenoble CEDEX 9, France.

R. Clayton, Seismological Laboratory, California Institute of Technology, 1200 California Blvd., Pasadena, CA 91125, USA.

A. Husker, V. Kostoglodov, and J. S. Payero, Instituto de Geofísica, Universidad Nacional Autónoma de México, Av. Universidad 3000, Ciudad Universitaria del Coyoacán, 04510 México, D. F., México. (vladi@servidor.unam.mx)

N. M. Shapiro, Laboratoire de Sismologie, Institut de Physique du Globe de Paris, 4 place Jussieu, Case 89, F-75252 Paris CEDEX 05, France. 